\title{
THINKING TOGETHER: MAKING COMMUNITIES OF PRACTICE WORK
}

\author{
IGOR PYRKO \\ University of Strathclyde Business School \\ Glasgow, G1 1QE, UK \\ VIKTOR DÖRFLER \\ University of Strathclyde Business School \\ COLIN EDEN \\ University of Strathclyde Business School
}

\section{INTRODUCTION}

The idea of Communities of Practice (CoPs) has been around for a longer time and it seems to find its way naturally into people's professional and even everyday language (Wenger, 2010). In many organizations where success depends on whether individuals manage to make the most of their knowledge and learning (Davenport and Prusak, 2000), CoPs are often seen as a useful idea and sometimes as an opportunity (Saint-Onge and Wallace, 2003, McDermott and Archibald, 2010, Liedtka, 1999). To put it simply, CoPs refer to groups of people who genuinely care about 'the same things' and who on that basis interact regularly in order to learn together and from each other (Wenger-Trayner and Wenger-Trayner, 2011).

Today CoPs are often conceptualized with reference to the notions of knowledge and knowledge sharing. However, the original conceptualization of CoPs (Lave and Wenger, 1991) was founded within a postmodern framework that tends to be skeptical about notion of knowledge (primarily as a term), associating it with appointed (or self-declared) experts who 'monopolize' the possession and creation of knowledge as their source of power. This explains why knowledge is in fact silent in CoPs, being approximated with the concepts of learning, meaning, and identity. At the same time knowledge sharing is a term often used inconsistently in the area of organization studies (Wang and Noe, 2010) and it is not always clear what it means: some authors write that knowledge sharing can signify one-directional knowledge transfers, others emphasize casual bi-directional or multi-directional exchanges of facts, and there are much deeper and more intensive notions such as 'meeting of the minds' and 'thinking together' that includes concepts such as 'knowledge creation' and 'knowledge discovery', while the same term is also often used with reference to dissemination of information such as research results.

As a consequence of these inconsistencies it is not clear whether it is the learning processes that lead to a CoP, or if it is a sense of community that needs to be instilled first which only then may provide the ground for engaged learning partnerships. This causes difficulties in defining the scope of CoPs and in planning the initiatives of developing such communities. For this reason in this paper we aim to go back to the original formulation of CoPs as situated learning in order to explore this concept from a process perspective where we aim to better understand what makes a $\mathrm{CoP}$, and what makes a $\mathrm{CoP}$ work well.

In this paper we adopt 'thinking together' with the above meaning and through four propositions we argue that 'thinking together' in this interpretation is essential for the CoP concept and it fills it with life. 


\section{THE PROCESS OF THINKING TOGETHER}

In this paper we suggest that it may be useful to 'bring knowledge back into CoPs'. One of the initial drivers behind the CoP concept was to oppose the back-then dominating view of knowledge as information that people simply place in their minds (Lave and Wenger, 1991). That aim in many ways has been met, just by looking at the example of the proliferating literature of practice-based view of learning in organizations (Corradi et al., 2010). It then appears that the CoP idea has matured enough after almost 25 years and it may be time to talk more explicitly about the role of knowledge. One must nonetheless be sensitive to the fact that the 'DNA' of the CoP concept is its foundation in identity and therefore compatible epistemological assumptions must essentially share these roots, which condition is met by Polanyi's (1962a) conception of 'Personal Knowledge'.

Central to Personal Knowledge is the idea of the tacit component which is a necessary ingredient of all knowledge; suggesting that knowledge can only exist within human minds and is necessarily grounded in the tacit dimension and thus "we can know more than we can tell" (Polanyi, 1966a: 4). To put it differently, the tacit dimension can be thought of as the bottom of an iceberg which stands for the chief part of what people know and underpins everything people know, and hence "a wholly explicit knowledge is unthinkable" (Polanyi, 1966b: 7).

Thus the tacit dimension warrants that the personal coefficient is present in all knowing. Knowledge is developed through 'indwelling', which is an aspect of the knowing processes that accounts for learning. Indwelling means that as people engage in knowing with uncritical commitment, they increasingly dwell on things (e.g. tools, theories, rules) they attend from the particulars to the focal part of performance as if they were parts of their body (see also Dörfler and Ackermann, 2012). So the more they use, for instance, a mathematical theory for solving mathematical problems in a meaningful way, to the bigger extent their command of that mathematical theory becomes a part of who they are. This kind of acceptance resulting from indwelling is called 'interiorization' and it can only be achieved by investing one's identity in the practice (Polanyi, 1962a, 1962b, 1966a, 1966b).

Consequently, Personal Knowledge bears a number of implications for CoPs. Knowledge is not acquired or gained, but developed in practice (Orlikowski, 2002, Gherardi, 2000, Nicolini, 2011). The dissemination of highly tacit knowing is more laborious and hence more costly than of decontextualized knowledge such as written articles and documents (Sveiby, 1996), but decontextualized knowledge needs to be first interpreted through personal acts of knowing (Tsoukas, 1997). Thus knowledge sharing appears central to cultivating CoPs, however this process must imply mutual engagement (Wenger, 1998) which characterizes CoP members' intensive, committed, and mutual learning interactions. This calls for a view of knowledge sharing where knowledge is not transferred in a literal way like an object, but it is re-recreated by knowers during those very acts of knowing (Bechky, 2003, Von Krogh, 2011), leading our argument to McDermott's knowledge sharing as thinking together. Knowledge sharing understood as thinking together is more demanding than a 'quick question' with no obligation to find an answer (Pentland, 1992: 537), it is about people understanding the problem and then shaping their knowledge to it (Cross et al., 2001: 105), and it "entails self-observation, reflection, and immersion in the routines of the master, as much as it does observation and imitative learning by the apprentice" (Von Krogh, 2011: 406). Thus as people think together about a problem they genuinely care about, their indwelling becomes synthesized in the fleeting moment, and this can lead to the creation of new knowledge (Dörfler, Baracskai, \& Velencei, 2015). 
As a result, thinking together shows that it is not just any kind of learning that brings a $\mathrm{CoP}$ to life, but rather a mutual engagement of frequently very diverse people who manage to relate to each other as they think together about problems that they all care about. Whilst less demanding exchanges of facts and insights of course certainly can be productive, these alone are insufficient to provide the richness and energy necessary to sustain mutual engagement over time or to attract others to joining a shared practice. We expect that the emphasis on the process of thinking together may help us to gain a better understanding of the original formulation of CoPs as situated learning and as we explore this concept from a process perspective where we achieve better understanding of what makes a CoP, and what makes a CoP work well. Through this we hope to provide practitioners with a useful point of focus for developing and fostering such communities in their organizational settings.

\section{METHODOLOLOGICAL APPROACH}

The empirical study was conducted in the National Health Service (NHS) Scotland. We present cases from two different areas of NHS Scotland, namely: dementia and sepsis. The empirical study had a qualitative character and it comprised of 30 semi-structured interviews and loose conversations with an average length of 1 hour each, and they took place in various hospitals and NHS offices across Scotland. A mix of purposive and snowball sampling was used (Biernacki and Waldorf, 1981, Teddlie and Yu, 2007), as the mangers in the NHS Education for Scotland were helping us to arrange the interviews with practitioners who expressed interest in the topics relevant to the study and were from CoPs at different stages of maturity. The participants were all healthcare practitioners (i.e. not patients, caretakers, etc.) and the topics discussed covered social learning, their experience of CoPs, and learning culture at their immediate workplace with additional discussion on how each of these translated into better performance. Thus, following March, Sproull, and Tamuz (1991) we attempted to 'learn richly' from this sample of practitioners by paying attention to the specific context of the particular CoPs, looking at the multiple aspects of the interview material, and thinking reflexively about its alternative interpretations. The gathered data was rich and messy, and hence it called for a method of analysis which could help to structure it, to make sense of it, and to communicate the research results in a simple way, while not losing too much of its complexity.

Our way of managing the complexity of empirical material was through applying a causal mapping method (Hodgkinson and Clarkson, 2005, Huff, 1990, Eden, 1992) in the analysis of data. The structure of causal maps, i.e. directed graphs, emerges from causal relationships of concepts represented by short phrases that are linked by unidirectional arrows (Eden et al., 1992, Laukkanen, 1994). An essential consideration for all causal maps is that they do not result in 'complete picture' of someone's thinking, rather they offer an imperfect representation of their thinking, which in turn may be useful in addressing a given problem. We thus mapped each interview using the Decision Explorer software, and the emergent structure of statements and causal arrows stemmed from the participants' contributions. Subsequently, in the same software we were able to run useful analytical functions: e.g. central analysis (i.e. finding statements with the highest impact on the map), clusters of concepts, or loops (i.e. self-reinforcing vicious or virtuous relationships between concepts which might be of considerable significance). This analysis in turn helped us to both structure our findings and to identify the relationships between the key patterns in the empirical material, consequently informing our discussion. 


\section{DISCUSSING THE FINDINGS}

The first case which we discuss took place in the area of dementia, which is "a syndrome (a group of related symptoms) associated with an ongoing decline of the brain and its abilities" including problems with memory loss, language, or thinking speed (nhs.uk, 2014a). In the UK an important role in helping patients with dementia is performed by Allied Health Professionals (AHPs) including a number of professions specializing in supporting people in their recovery. AHPs include, among others, occupational therapists, speech and language therapists, or art therapists (scotland.gov.uk, 2014). In our case a group of AHP leaders wanted to bring together professionals who otherwise did not have mutual access to one another's knowledge. They set up a discussion forum labelled ' $\mathrm{CoP}$ ' which was hosted by the health services' library, and which was fully open to the public with the expectation to allow reaching a wider audience. They also started to use the forum to publish a quarterly newsletter about dementia which was based on the stories received from practitioners across Scotland about their day-to-day work.

However, while the practitioners would regularly send their contributions to the newsletter, the online forum did not encourage sufficient interactions to build an engaged community around it. We identified a vicious loop: people can only submit their resources via administrators, which leads to the administrators publishing the newsletter, which leads to people engaging in the shared practice through the newsletter and not through direct conversation in the forum, which leads to the $\mathrm{CoP}$ website being a place for resources rather than a place for conversation, which then self-sustains the loop. Thus by digging into the 'nub of the issue' it became clear that the reason for little engagement was not lack of time on part of the practitioners, but the absence ongoing conversations and existing learning partnerships to justify their time spent on the forum.

Our second case took place in the area of sepsis, which NHS defines as "a common and potentially life-threatening condition triggered by an infection" (nhs.uk, 2014b). In our discussion we concentrate on a team specializing in diagnosing and treating sepsis called the Critical Care Outreach Team from the Borders General Hospital. The team comprise five senior nurses who specialize in sepsis and who all have experience in intensive care. Not only are they responsible for quickly responding to the cases of sepsis in the hospital, but in order to meet the goal of improving early recognition of sepsis they educate the staff in the wards, provide them with supporting tools and systems, and help to improve their communication about sepsis.

All of these actions have become the ingredients of the hospital's sepsis-based practice, with a community of different kinds of practitioners organized around it. Practitioners from across the hospital identify themselves with sepsis because it is relevant to their work since it may happen to their patients in the most unexpected moments. As a result they genuinely care and think together about various real-life problems surrounding sepsis and they are willing to invest their time in learning more about it. In effect we can look at the Outreach Team as a core group of a super-performing $\mathrm{CoP}$ with high impact, and with more peripheral members coming from different departments. As practitioners invest their identity in thinking together about what it means to treat sepsis, they not only acquire the useful facts and definitions but they become competent in translating their learning into practice.

In the dementia case the community leaders' original goals and strategy seemed very promising: they wanted to bring practitioners in their area out of isolation to enable them learning from one another's experience. However, the main issue with the execution of their strategy was that they did not prepare the avenues for thinking together on their discussion 
forum. It seemed as if they thought that it was sufficient to set up a website for discussions, to promote it, and then to wait and see what was going to happen. What the community leaders were really lacking was a group of people who could drive the learning. They could have helped that situation by identifying some more specific key problems and hot topics that were relevant to the organization and which the practitioners clearly cared about. Moreover, they could have tried to connect people around those problems and then support them or even join that core group if the others felt comfortable about their presence. Without thinking together about the problems there was not enough mutual engagement that could sustain a shared practice and there was not enough value to attract 'lighter' forms of participation. Meanwhile the codified stories published in the newsletter (whilst certainly highly valuable) was no substitute for thinking together. The point of setting up a discussion forum was merely a step towards cultivating a CoP, but definitely not the moment of actually establishing one. Without the focus on thinking together, and by not attempting to make an informed link between the experienced reality and the theory, the CoP concept was more of a distraction and not a help for making more of peoples' learning.

Conversely, in the sepsis case there was a thriving community because their members could see value in interacting regularly since they were holding stake in similar problems or hot topics. The practitioners from various departments in the hospital were invited to learn together and from each other about sepsis. Instead of attempting to control what was happening in the wards, the team were taking the role of non-judgmental peer-mentors who were supporting the other practitioners in developing their knowledge about sepsis 'in practice'. That gave birth to a community formed around the real-life need of recognizing sepsis early, which translated into a much better treatment of patients with sepsis within the whole hospital. All of these illustrations highlight that it is important to look at community development as a continuous process where people think together regularly about real-life problems. As soon as thinking together at the heart of the community stops, it may quickly begin to lose its rhythm and vibrancy (or it may never come into life in first place). Our first three propositions are therefore:

Proposition 1: Thinking together about real-life problems which people genuinely care about gives life to CoPs, and not the other way round.

Proposition 2: The core group of a CoP is defined by thinking together and not by having a role in supporting the community or by holding stake in its wellbeing.

Proposition 3: Paying close attention to the changing world when thinking about the community, its practice, and its domain is crucial. It is easy enough to fall in love with an imaginary picture of a CoP that is rather detached from reality. When fostering CoPs we need to accept the evolving and dynamic nature of learning and build on it.

Based on the discussion so far we now comment on the scope of the CoP concept as it does not appear to be a straightforward matter. CoPs are often associated with informal groups, discussion clubs, social networking sites, groups of interest, or peer-support groups. However, what makes a CoP is not its informality, openness for ideas, or flat structure. These can certainly be common and desirable ingredients of CoPs; yet CoPs can also be formal, official, or take the form of close-minded cliques which deny outsiders access to their learning. While CoPs do not have to be informal, they are fundamentally self-governed and driven by peoples' regular thinking together. The scope of CoPs therefore includes those people who engage in thinking 
together regularly, and those individuals who have meaningful access to that thinking together, i.e. an access that entails at least elementary understanding of what is talked about and the ability to contribute to the shared practice (as in legitimate peripheral participation). Thus to the bigger extent a social space can be characterized by sustained thinking together that is enriched by less intensive forms of participation, the more sense it makes to call it a CoP.

Our findings also indicate that the value of this concept can be very limited when at least its most basic conceptual frameworks are not explored. This is because cultivating CoPs is not about deciding that 'one wants a CoP', but about making conscious efforts to learn more about one's own learning and ways of improving it. That requires establishing a stronger link between the lived experience of what it means to learn socially with other people, and with the CoP theory which aims to shed light on the complexity and the richness of such partnerships. The more intentional use of theory could have helped to overcome the community challenges in the dementia case, and to potentially make more of the existing social learning in the sepsis case. As a result our fourth, and final proposition is:

Proposition 4: The scope of CoPs is delineated by the process of thinking together happening at the core of such communities, and by the less intensive forms of participation which effectively influence that thinking together in a smaller or bigger way. Thus, CoPs can be understood as taking a holistic view on thinking together that is sustained over time.

\section{CONCLUDING REMARKS}

The idea of thinking together is as important from the academic point of view as it is from the practitioner point of view. It originates from the empirical part of the research: this was the term the practitioners could make sense of when trying to conceptualize CoPs. From an academic aspect, it elaborates the very foundation of the CoP concept by explaining the learning processes happening at the core of such communities and assigning them a central role. It takes the concept back to its roots in situated learning and it highlights the dynamic process-nature of CoPs. Thereby it moves the CoP concept further away from a stable ontology, simultaneously keeping it as a dual construct (i.e. a CoP is both entity and process at the same time) because thinking together does not deny the social structure which originates from learning. It also makes it easier to draw the scope of this concept where those who belong to a CoP are those who engage in thinking together plus those who have meaningful yet less regular access to it. Another use of thinking together is in clarifying the notion of knowledge sharing which is very popular in the literature, especially in the field of knowledge management, and which can be relevant to the practitioners. Thinking together highlights the overly generic way in which knowledge sharing is typically used, and it delineates from it the intensive mutually engaged learning that characterizes CoPs and which can lead to new knowledge. In terms of a Polanyian epistemology, it treats the assumption that knowledge can be literally transferred from one person to another as naïve, and instead it stresses that tacit knowledge is shared only in the sense that it is redeveloped but not acquired or replicated as people discover one another's performance in practice and they learn together and from each other.

\section{REFERENCES AVAILABLE FROM THE AUTHORS}

